\title{
Trends and Challenges of Knowledge Management Technology from Malaysia's Perspective
}

\author{
Subashini Ganapathy ${ }^{\mathrm{a}, 1}$, Zulkefli Mansor ${ }^{\mathrm{a}, 2}$, Kamsuriah Ahmad ${ }^{\mathrm{a}, 3}$ \\ ${ }^{a}$ Center for Software Technology and Management, Faculty of Information Science and Technology, Universiti Kebangsaan Malaysia, \\ 43650, Bangi, Selangor, Malaysia \\ E-mail: ${ }^{1}$ P93081@siswa.ukm.edu.my; ${ }^{2}$ kefflee@ukm.edu.my; ${ }^{3}$ kamsuriah@ukm.edu.my
}

\begin{abstract}
Knowledge Management (KM) is one of the most important capitals in this era. Properly managing knowledge would help in problem-solving and decision making. However, managing knowledge is not a simple task. Malaysian agencies are predominantly known as knowledge-based organization. KM has been adapted into both public and private agencies quite some time. By practicing KM, the organization comprehensively gather, create, sharing, analyzes the knowledge for continuous organizational learning. However, an organization must continuously evaluate the effectiveness of their KM practices to remain competitive by looking at the challenges that are faced. Therefore, the organization should further investigate the trends, challenges, and issues to boost the use of knowledge efficiently. Thus, this paper presents a review of existing literature on KM influencing factors in public and private agencies, especially in Malaysia. The challenges were identified from recent existing studies from the year 2012 until 2019. This study gives an insight into current trends of KM studies and challenges which contributes to KM practices and implementation in Malaysia. The study revealed that management and leadership support which seemed to be lacking and was the most challenging factors in KM practices through recent studies.
\end{abstract}

Keywords - KM; success factors; influencing factors; private agency; public agency.

\section{INTRODUCTION}

Knowledge Management (KM) is vital for organizations to maximize knowledge creation, storing, sharing and dissemination of resources. By doing so, the organization would able to improve decision making and would tackle issues on lack of information retrieved. KM is essential aspects of organizations around the globe which focus on efficient and effective ways to manage knowledge [1]. Accompanied by digital transformation, the public and private agency around the world uses the application of Information Communication Technology (ICT) to increase their productivity. Collectively, the concept of KM has been exercised in various fields, especially in engineering, human resource management, medicine, business, and science.

In recent years, there are several growing types of research done on KM practices and implementation. Concept of KM brought in by a researcher named Nonaka in 1994 through his research. However, discourse on this concept is still not comprehensively discussed. There are limited studies which are done to review current studies on $\mathrm{KM}$, specifically in Malaysia. In that case, there is a need to systematically review the current trends and challenges related to KM practices. These challenges must be addressed in-depth in any organization to provide the best practices for them to stand out in their KM strategies [2].

According to recent studies in Malaysia, public agencies were examined mainly in terms of education, entrepreneurship development, banking, human resources, health, and public agencies. Fourth Prime Minister of Malaysia raised KM initiatives in 1991 on the values of knowledge management. He urged that the organization must transmute the economy towards a knowledge-based economy. Recently, in the year 2016, Ministry of Trade and Industries of Malaysia reported that the process of knowledge transfer within most industries in Malaysia failed to ultimately achieve the goals in most of the organizations in Malaysia. Therefore, the main objectives of this paper are to address further the factors affecting the practices of KM. These factors include challenges from people, process, and technological perspectives. The second objective, to explore the trends of the KM practices, specifically in Malaysia. By referring to the inductive literature studies review, these are the research question which is derived:

RQ1: What are the recent challenges studied by researchers based on the available literature review?

RQ2: What are the most factors that influenced KM practices based on the available literature review? 


\section{MATERIAL AND METHODS}

KM brings in the concept of creating, sharing, storing and use of knowledge. Organizational objectives and decision making can be archived in the right manner by using appropriate knowledge. Wiig introduced the term of KM in the year 1986 [3]. According to Nonaka in 1994 [4], an asset of knowledge is categorized into two categories which are tacit knowledge and explicit knowledge. Tacit knowledge is knowledge which is unmanageable. It's hard to be documented and describe because of this knowledge comes from human experience and perception. Explicit knowledge usually can be easily documented and validated. The only challenge is that right explicit knowledge must be accessible to the needs.

According to Nonaka, knowledge is created, shared, stored, and distributed through a collaborative environment. New implementation of knowledge comes from exploitation and transmutation from an original idea from a human. Information Technology (IT) plays crucial roles in the knowledge creation process as a supporting. Knowledge which is created needs to be stored in a platform so that it can be shared with others. Technology plays a vital role to support knowledge storing activity. With the cutting edge of ICT infrastructure, knowledge can be stored effectively in the right manner. Stored knowledge can be shared by using the appropriate sharing platform. By knowledge sharing, more productivity can be seen in any organization. And finally, knowledge can be disseminated so that relevant information and knowledge reach the concerned person.

\section{A. History of Knowledge Management}

KM has arisen for a long time since the 70s. The evolution and achievement of knowledge management can be seen from various contributions. Ahead of time in the 1970s, the term KM research was introduced by Peter Senge, Peter Drucker and Paul Strassman from the United States [5]. The direction of Peter Senge [5] is more on organizational learning as an ethical element of KM. Paul Strassman and Peter Drucker [6] had a direction to the importance of knowledge as a source of the organization as well as information enhancement. On the other hand, Leonard Barton examined KM strategies with his famous case study called "Chaparral Steel" case study.

In the 1980s, we could see some developments in smart systems and artificial homeowners who also mapped the concept of KM. These basics, as we know, is focus on the metaphysical terms of "knowledge-based systems", "engineering" and "knowledge acquisition" in the world of computing. KM became popular in the management field and came into sight in journals, especially in the business field.

Also, in the 1990s, it was articulated to be an era full of management theory in which several consulting firms took part in KM platforms. Japanese theorists, namely Nonaka and Takeuchi, brought in several models to assess the concept thoroughly, such as the Nonaka model. Japan, primarily, used this concept to date to become the most innovative industry. Europe and U.S companies started to adopt $\mathrm{KM}$, and their research became wide, particularly in business conferences. During this time, there were several publications, conferences and seminar were held to general the KM concepts by introducing to its benefits in the organization.

In the year 2003, KM became commercialized to the academic field where there were more than a hundred organizations, including universities, and library school adapts KM by proposing KM degree and courses [7]. During this era, many people start to apply KM and gain benefit. There are a quite number of definitions of $\mathrm{KM}$ been identified in an informal survey by Dalkir in the year 2005 from various domains. In the universities point of view, KM implementation indirectly devotes to profit from them. And it is also considered as a key to reach a competitive reward. Knowledge is uneasy to codified unless there is a perceptive and contribution of skills and experience from the educators [8].

\section{B. Trend and Studies of KM in Malaysia}

The concept of knowledge management is an important activity that must be implemented effectively by an organization. Various studies have been done in Malaysia related to KM practices. KM understanding in the Malaysian context is difficult because research is limited [9]. Knowledge management was born in line with the beginning of the "Multimedia Super Corridor (MSC)" development in the 1990s in Malaysia. There are quite numbers of studies done in Malaysia, but not comprehensively done.

In general, most public, or private organizations have adopted the concept of KM in Malaysia. The public agency term refers to a functioning body of the state, federal, district, local and municipal levels. This agency includes all agencies, including government corporations, armed forces and departments, agencies and various units providing public services. Organizations in Malaysia in particular, whether public or private agencies are still unable to manage their knowledge [9] effectively. This is due to the uncertain challenges faced by the organization itself.

The concept of KM has been practiced in most private agencies compared to the public agency, for example, in MAMPU, MIMOS, Bank Negara Malaysia, Siemens, Nokia Malaysia, Tenaga Nasional Berhad, Petronas and Telekom [10]. Various KM systems are used as support for the creation, sharing, storage and dissemination of knowledge. $\mathrm{KM}$ has been brought out as a key factor in ensuring organizational success. Table 1 shows a summary of the research done on KM practices in Malaysia.

Several studies have been conducted by focusing on the KM importance to local organizations [11]. Yahya and Goh did the first study [12] in Malaysia. The study shows the capability of $\mathrm{KM}$ in the human resource management department. The study probes the relationship between knowledge management as well as human resource management. Knowledge process such as knowledge acquisition, documentation, knowledge transfer and knowledge application, predominantly acts as a major concern in organizational knowledge. In particular, the four elements of human resource management such as decision making, training, appraisal, and compensation and rewards are studied in five areas of knowledge management process such as (knowledge acquisition, knowledge documentation, knowledge transfer, knowledge creation, knowledge applying). The findings showed that knowledge-based 
organizations require different management approaches from non-knowledge organizations. Therefore, it is concluded that the part of human resource management also plays a major role. In terms of workers, the main concern should be on promoting creativity, leadership, quality, and finally, problem-solving skills.

TABLE I

LiST OF STUDIES OF KM IN MALAYSIA

\begin{tabular}{|c|c|c|c|}
\hline Author / Year & Research title & Research sample & Outcome / findings \\
\hline $\begin{array}{l}\text { Yahya \& Goh } \\
(2002)\end{array}$ & $\begin{array}{l}\text { Managing human resources towards } \\
\text { achieving efficient knowledge management }\end{array}$ & Malaysian firms & $\begin{array}{l}\text { Knowledge-based organizations } \\
\text { involved different management } \\
\text { approaches than non-knowledgeable } \\
\text { organizations. }\end{array}$ \\
\hline $\begin{array}{l}\text { Syed Ikhsan \& } \\
\text { Row-land } \\
(2004)\end{array}$ & $\begin{array}{l}\text { The study of the relationship between the } \\
\text { organizational elements and knowledge } \\
\text { transfer performance in Malaysian public } \\
\text { organizations }\end{array}$ & $\begin{array}{l}\text { Ministry of Entrepreneur } \\
\text { Development Malaysia }\end{array}$ & $\begin{array}{l}\text { Organizational culture affects KM } \\
\text { practices. }\end{array}$ \\
\hline Chong (2006) & $\begin{array}{l}\text { KM critical success factors: Importance } \\
\text { versus implementation in Malaysian ICT } \\
\text { companies }\end{array}$ & Malaysian ICT company & $\begin{array}{l}\text { There are significant deviations } \\
\text { (Example, org culture, structure, } \\
\text { training, benchmarking, to mgt support, } \\
\text { IT infrastructure) considered as } \\
\text { necessary }\end{array}$ \\
\hline Chong (2006) & $\begin{array}{l}\text { Empirical evidence of KM issues and KM } \\
\text { performance outcomes. }\end{array}$ & $\begin{array}{l}\text { Multimedia Super } \\
\text { Corridors companies }\end{array}$ & $\begin{array}{l}\text { There is a significant relationship } \\
\text { between performance and the KM } \\
\text { current issues }\end{array}$ \\
\hline $\begin{array}{l}\text { Wei, Choy \& } \\
\text { Yeow (2007) }\end{array}$ & $\begin{array}{l}\text { An empirical analysis of KM implementation } \\
\text { in the Malaysian telecommunication industry }\end{array}$ & $\begin{array}{l}\text { Telecommunication } \\
\text { organizations in } \\
\text { Malaysia }\end{array}$ & $\begin{array}{l}\text { Organizations are aware of the necessity } \\
\text { of all KM factors but short of } \\
\text { implementation }\end{array}$ \\
\hline $\operatorname{Lim}(2007)$ & $\begin{array}{l}\text { Knowledge Management in the Malaysian } \\
\text { aerospace industry }\end{array}$ & $\begin{array}{l}\text { Malaysian aerospace } \\
\text { industry }\end{array}$ & $\begin{array}{l}\text { The framework consists of four stages: } \\
\text { the cultivation of consciousness; } \\
\text { objective definition; strategy-making; } \\
\text { and implementation of actions. }\end{array}$ \\
\hline $\begin{array}{l}\text { Chong Chin Wei } \\
(2009)\end{array}$ & $\begin{array}{l}\text { Is Malaysian Telecommunication Industry } \\
\text { ready for KM? }\end{array}$ & $\begin{array}{l}\text { Telecommunication } \\
\text { industry }\end{array}$ & $\begin{array}{l}\text { Strategies and processes are important } \\
\text { and critical elements but cannot be } \\
\text { effectively implemented. }\end{array}$ \\
\hline $\begin{array}{l}\text { Nazatul Aisha } \\
\text { Md Ramin } \\
(2013)\end{array}$ & $\begin{array}{l}\text { Implementation of Knowledge Management } \\
\text { at the Government Research Institute in } \\
\text { Selangor, Malaysia }\end{array}$ & $\begin{array}{l}\text { Government Research } \\
\text { Institution }\end{array}$ & $\begin{array}{l}\text { People, technology and organisational } \\
\text { factors influence the KM practices. }\end{array}$ \\
\hline $\begin{array}{l}\text { Javad Moshari } \\
(2013)\end{array}$ & $\begin{array}{l}\text { Knowledge Management Issues in Malaysian } \\
\text { Organizations: Leaders' Perceptions }\end{array}$ & $\begin{array}{l}\text { Malaysian construction } \\
\text { companies }\end{array}$ & Classification of factors affecting KM. \\
\hline $\begin{array}{l}\text { Muhamadul } \\
\text { Bakir Hj. } \\
\text { Yaakub (2014) }\end{array}$ & $\begin{array}{l}\text { Knowledge Management Practices in } \\
\text { Malaysian Higher Learning Institutions: A } \\
\text { Review on Selected Cases }\end{array}$ & $\begin{array}{l}\text { Malaysian Higher } \\
\text { Learning Institutions }\end{array}$ & KM practices not yet become formative. \\
\hline $\begin{array}{l}\text { Elmahdee \& } \\
\text { Hashim (2014) }\end{array}$ & $\begin{array}{l}\text { Knowledge Management Practices in } \\
\text { Malaysian Construction Companies }\end{array}$ & Construction company & $\begin{array}{l}\text { The practice of KM is modest. } \\
\text { Knowledge storing is high, the practice } \\
\text { of applying and disseminating } \\
\text { knowledge relatively low }\end{array}$ \\
\hline $\begin{array}{l}\text { Norliya Ahmad } \\
\text { Kassim (2016) }\end{array}$ & $\begin{array}{l}\text { Knowledge Management Practices and } \\
\text { Organizational Performance in Malaysia } \\
\text { Government Institution }\end{array}$ & $\begin{array}{l}\text { Malaysia Government } \\
\text { Institution }\end{array}$ & $\begin{array}{l}\text { Organization performance is at a } \\
\text { medium-high level in the organization }\end{array}$ \\
\hline Norliya (2016) & $\begin{array}{l}\text { Assessing Knowledge Management Maturity } \\
\text { in a Telecommunication Company }\end{array}$ & $\begin{array}{l}\text { Telecommunication } \\
\text { Company }\end{array}$ & $\begin{array}{l}\text { There are positive, significant, and } \\
\text { moderate relationships between } \\
\text { leadership behavior and people and } \\
\text { network, between KM strategy and } \\
\text { leadership behavior, and between people } \\
\text { and network and KM strategy }\end{array}$ \\
\hline $\begin{array}{l}\text { Abang Azlan } \\
\text { Mohamad } \\
(2017)\end{array}$ & $\begin{array}{l}\text { Knowledge Management In Msc Malaysia: } \\
\text { The Role Of Information Technology } \\
\text { Capability }\end{array}$ & MSC company & $\begin{array}{l}\text { Knowledge conversion and knowledge } \\
\text { protection are positively and } \\
\text { significantly related to firm } \\
\text { innovativeness }\end{array}$ \\
\hline
\end{tabular}

A second study by Syed Ikhsan [13], a knowledge transfer process specifically evaluated in the public sector. The research indicates that the implementation of KM is the key to building up a competitive advantage. The outcome of the study showed that there is an absence of KM strategy in the organization. The study revealed that factor such as organizational culture affects KM practices. In another view, $\mathrm{Yu}$ [14] highlight that rigorous review of KM is necessary to ensure current benefits so that the organization continues to be competitive and have a positive view of the knowledgebased economy. 
Another study by Choy and Yeow [15] in the perception of Malaysia focuses on telecommunications companies. His research was given attention to KM implementation rather than learning and use of knowledge. It is found that there are substantial gaps between KM implementation and the critical success factor. Among the factors that have been discussed are business strategy, K-Map, K-Team and KAudit. The outcome of this study showed that strategies such as leadership, technology and culture related to $\mathrm{KM}$ are moderately implemented. The implementation of $\mathrm{KM}$ is on the commencing stage in the telecommunication industry.

Similar studies were done by [16], [17], which pay attention to telecommunications companies. To be precise, a study by [16] highlights the critical success factor that affects KM in terms of importance and its implementation. It is found that in his research, employees realized the grandness of KM concepts, but there is a lack of implementation. The same approach above can be seen in a study by [17] which simulate the relationship between leadership behaviors, individuals and networks. Through her study, it is found that there was a positive significant and moderate relationship between leadership behavior, networks and individuals, KM strategies and leadership behaviors, and between KM and networks and KM strategies. All the above studies point out that the telecommunications agency roleplays as a vital part in the flow of information in Malaysia perspectives.

The study by Wai [18] focuses on the aerospace industry in existing knowledge practices. The direction of his research specifically emphasizes on the factors that affect the use of KM and possibility study on the use of KM as strategic tools in the Malaysian aerospace industry. Senior staff members of the industry have been interviewed to acquire knowledge in the fields. A framework obtained in this study, which consists of four stages: cultivation of consciousness; objective definition; strategy taking; and execution of the action. Each of these stages involves some important elements for successful KM implementation. He also stressed that $\mathrm{KM}$ is a huge asset as a source of competitive advantage and wealth. Therefore, it is important to identify the important factors for KM success in the organization.

Other than that, various studies were also done in some government agencies, for example, a study by Ramin [19] carried out in Government Institutes Malaysia (GIM) and Malaysia Higher Learning Institution (MHLI) [20]. A study by Ramin [19], identified that there are three main factors that influence $\mathrm{KM}$ practices in an organization, namely people, technology and organizational factor. The outcome of this study exposed that, applying and knowledge managing in the organization was ineffective. This might result due to the lack of individualism factor that plays an important role in promoting organizational cultures, such as in learning and sharing. Whereby, a study by Muhamadul [20], shows that there is a need to create a formative standard to enable a systematic realignment of practices.

In the other perception, KM concept has also been researched in the construction field in the companies. Studies by Moshari [10] revealed the classification of factor that affect KM in Malaysian construction companies. The study indicated that there is a deficiency of objective and strategic of KM. He also stressed that the team-oriented personnel department focus is more important compared to technological supports in knowledge sharing practices. Meanwhile, a study by Elmahdee [21] in construction companies, exposed that $\mathrm{KM}$ practices in the organization seem to be simple. Knowledge storing activity relatively active, and knowledge disseminating and knowledge enforcing seems to be at a low level.

The speedy enhancement of Information Communication Technology (ICT) has become a fresh challenge for KM, although it has been separated from another point of view. The rapid gain in ICT is found to be a challenge as it has produced a vast amount of information worldwide that require organizations to streamline their technology and knowledge in this direction. Technology limitations can be seen as a challenge by some researchers as many KM processes require Information Technology (IT) for efficient KM practices. Infrastructure information systems depend on the use of network technologies such as the internet and communication systems to transfer knowledge. This is a major contributor to the KM knowledge application [10]. It can be concluded that technology is essential for an efficient KM system.

Usage of technology plays important roles in creating, storing and dissemination of knowledge. While technology is a huge challenge because the trend of technology keeps changing rapidly and the use of these latest technologies promote success in the practices. However, a study by Alias [22] highlighted that by using simple technology, and wellequipped ICT infrastructure could also foster KM practices in terms of knowledge sharing. However, when it comes to knowledge sharing, the individual is quite cooperative, and the practices high, but the practice of deploying and disseminating knowledge that is the primary objective of $\mathrm{KM}$ is relatively low.

Some research has also been done in the Multimedia Super Corridor (MSC) companies in regards to KM practices. A study by Chong [23], examines the benefits of $\mathrm{KM}$ to the organization. His study also suggests how KM endeavors shall be consistently managed and assessed in order to success. A recent study by Azlan [24] focuses on $\mathrm{KM}$ practices in MSC companies. The study was discovered on the roles of IT with the KM processes. Impact of IT was identified based on the acquisition, application, conversion and protection. He highlights that the innovativeness of the firm depends on the supports of high technology. IT has the capability as an intermediate between knowledge protection and knowledge conversion.

The literature review method has been used as a research methodology with the adaptation of systematic literature reviews (SLR) [25]. Based on the existing literature [26], there is some stage under SLR that need to be focused. The stages are planning where the research questions are determined, secondly conducting and reporting. Fig 1 shows the complete stages in adapting the SLR approach. The researcher used the same approach to answer the research questions. SLR approach used to identify the Knowledge Management trends and challenges, especially in Malaysia. In the planning stage, the research question (RQ) derived as per mentioned in the introduction. The research questions are as follows: 
RQ1: What are the recent challenges studied by researchers based on the available literature review?

RQ2: What are the most factors that influenced KM practices based on the available literature review?



Fig. 1 SLR research model

The second stage includes selecting and evaluating relevant studies. In this case, relevant studies on the KM practices in public and private agencies of Malaysia were chosen. Studies beyond the Malaysian perspectives will be excluded from this study. Stage 3, for locating the studies, the search criteria derived from the keywords from this current research questions study. Boolean operators used in this study to search for the criteria for databases. Meaning that the related paper based on the research question were chosen with the usage of search criteria of OR. For example, (1) knowledge management challenges OR KM challenges and (2) knowledge management practices in Malaysia OR $\mathrm{KM}$ practices in Malaysia.

In stage 4, analysis has been done to obtain the challenges that the agencies being faced in selected studies. The challenges are reviewed from the literature search that was selected based on studies from the year 2012 until 2019. Selective studies were reviewed to find the appropriate challenges based on the Malaysian perspectives from the public as well as in the private agency.

Stage 5 in reporting, 15 papers most recent (from the year 2012 to 2019) was selected, an analysis was conducted to answer RQ1. A number of 19 related factors found to be challenged in practicing KM (Table 2). The list of references sourced from the respective databases including Science Direct, IEEE, Springer and Elsevier and Scopus.

\section{RESULTS AND DISCUSSION}

This section showed the result of the study. The challenges are retrieved from the selective research studies from both private and public agencies in Malaysia to answer RQ1. The challenges are mentioned as in Table 2, and the reference number highlighted based on its challenge. The challenges are studied based on the current literature from the year 2012 until 2019.

TABLE II

LIST OF CHALLENGES

\begin{tabular}{|c|c|c|c|c|c|c|c|c|c|c|c|c|c|c|c|}
\hline \multirow{2}{*}{ Challenge } & \multicolumn{15}{|c|}{ Ref } \\
\hline & [28] & [29] & [10] & [30] & [20] & [21] & [31] & [32] & [33] & [9] & [34] & [24] & [35] & [36] & [37] \\
\hline Sharing culture & & $\sqrt{ }$ & & $\sqrt{ }$ & & & & & $\sqrt{ }$ & & $\sqrt{ }$ & & & & \\
\hline Teamwork & & & $\sqrt{ }$ & & & & & & $\sqrt{ }$ & $\sqrt{ }$ & & & & & \\
\hline Management leadership/support & & & $\sqrt{ }$ & & & & & & $\sqrt{ }$ & $\sqrt{ }$ & & & & & \\
\hline Human behaviour & & & & $\sqrt{ }$ & & & & & $\sqrt{ }$ & $\sqrt{ }$ & & & $\sqrt{ }$ & $\sqrt{ }$ & \\
\hline Individualism & & & $\sqrt{ }$ & & & & & & $\sqrt{ }$ & & $\sqrt{ }$ & & & $\sqrt{ }$ & \\
\hline Document confidentiality status & & & & & & & & & & & $\sqrt{ }$ & & & & \\
\hline Task \& responsibility & & & & $\sqrt{ }$ & & & & & & & & & & & \\
\hline $\begin{array}{c}\text { Communication/flow of } \\
\text { information }\end{array}$ & & $\sqrt{ }$ & $\sqrt{ }$ & $\sqrt{ }$ & & & & & & & $\sqrt{ }$ & & & & \\
\hline ICT infrastructure & & & & & & & & & $\sqrt{ }$ & & $\sqrt{ }$ & $\sqrt{ }$ & $\sqrt{ }$ & & \\
\hline ICT tools & $\sqrt{ }$ & & & & & & & & $\sqrt{ }$ & & $\sqrt{ }$ & $\sqrt{ }$ & $\sqrt{ }$ & & \\
\hline ICT know-how & & & & & & & & & & & $\sqrt{ }$ & $\sqrt{ }$ & & & \\
\hline Decision making & & & & & $\sqrt{ }$ & & & & & & & & & $\sqrt{ }$ & \\
\hline Training & & & & & $\sqrt{ }$ & & & & $\sqrt{ }$ & & $\sqrt{ }$ & & & & \\
\hline Reward & $\sqrt{ }$ & & & $\sqrt{ }$ & $\sqrt{ }$ & & & & & & $\sqrt{ }$ & & & & \\
\hline $\begin{array}{c}\text { Performance } \\
\text { appraisal/measurement }\end{array}$ & & & & & $\sqrt{ }$ & & & & & & $\sqrt{ }$ & & & & \\
\hline Staff turnover & & & & & & & & & & & $\sqrt{ }$ & & & & \\
\hline knowledge structure/process & & & & & & $\sqrt{ }$ & & $\sqrt{ }$ & & & & $\sqrt{ }$ & $\sqrt{ }$ & & $\sqrt{ }$ \\
\hline Return of Investment & & & $\sqrt{ }$ & & & & & & & & & & & & \\
\hline KM strategy & & & & & & & $\sqrt{ }$ & & & $\sqrt{ }$ & & & & & \\
\hline
\end{tabular}

The most influenced factor was identified in this study by referring to an existing paper. This review was done to answer the second research question (RQ2). Frequency of challenges, as shown in Fig 2 below, is derived from existing studies. It showed that the management and leadership support $(16.1 \%)$ factor was the main challenges faced by most of the agencies in Malaysia. Other than that, factor such as individual roles also seemed to be very important in promoting effective KM practices the organization.
The study revealed that there is a lack of individual commitment to KM practices. In general, knowledge creation basically derived from an individual perspective. Therefore, without the proper individual involvement or commitment to this practice, it is found that there will be a lesser teamwork environment. Another factor that contributes to poor KM practices in the organization either in public or private agencies is that there is a lack of "teamwork" skills. Teamwork skills were also necessary to contribute to proper 
knowledge sharing within the team members in the department. These two factors (individualism and teamwork) are related to each other and determine knowledge creation, gathering and knowledge sharing.

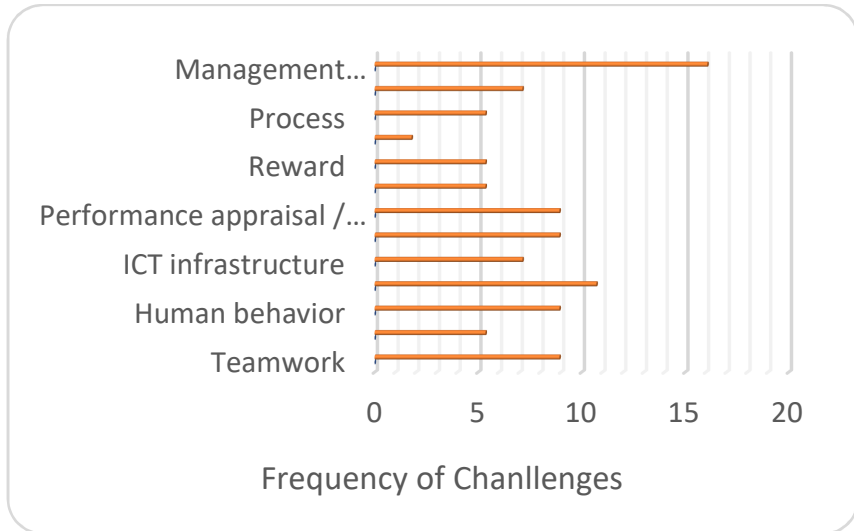

Fig. 2 Frequencies of recent challenges by studies (2012-2019)

The other reason KM initiatives seem to be slow could be because of less awareness of the importance of KM. A study by [22] revealed that the KM process, such as knowledge application, seems hard to bring up. Perhaps, as the solution, an adequate awareness campaign should be conducted to expose the potential benefits of $\mathrm{KM}$ practices in organizations. Other than that, proper training should be given so that the entire employees in the organization will get exposed to the KM initiatives in the first place. Ali [27] suggests a new approach called "mentorship" for training purpose. This kind of mentorship is a relatively new kind of training which will be useful for all employees in practicing KM collectively. This can be achieved through mentor support. For example, each employee must have a mentor so that self-confidence attitude can be built among the employee with the mentor support. This can be done by pairing up the experienced employee with the other employees who are having less experience in the organization for collaborative learning. By doing so, knowledge sharing between young and senior employee generally would be improved through team-teaching [38].

To eliminate the "individualism", one should be more competent by mingling with the other colleagues so that collaborative knowledge sharing can be obtained. Through this collaboration, new ideas and skills can be learned in the first place. This will enhance a positive learning environment in the organization. Apart from that, the management of the organizations should motivate the employees by giving them some sort of recognition as well as rewards to promote better knowledge processes such as creation, sharing, storing the source of information. By providing appropriate monetary reward also, knowledge process such as knowledge sharing can be mended [38]. The productivity of work will increase and indirectly will promote efficient learning in organizations. The reward factor has a correlation with the human behavior factor. The employee's behavior is likely to change if there is proper recognition and reward was given to the regular $\mathrm{KM}$ practices. This will automatically boost the knowledge sharing process and will promote spectacular performance and continuous surrogate learning.
On the other hand, top management should practice having an interaction with their employees. Meaning that top management should take part in KM practices for collaborative learning. Supports from the top management are the highest motivation factor for every department in the organizations. Other than that, the involvement of top management also found to be important for raising and subbing tacit knowledge in the organization. So, without proper involvement of top management in $\mathrm{KM}$ practices might not prominently motivate employees in each of every department in the organizations.

Molding a good physical structure, for example, in organizational structure, culture and technological aspects are necessary as a part of contributing successful KM life cycle (knowledge creation, storing, sharing and dissemination). And all this effort should come from top management. Management leadership and top management support found to be a challenging factor through this study. Without top management supports from this perspective seems to be one of the moderate factors that will influence $\mathrm{KM}$ practices in any organizations.

\section{CONCLUSIONS}

$\mathrm{KM}$ practices in organization enable positive environment by sharing experiences, perspective, and information to assure the information and knowledge to be accessed at the right time and the right place. Effective practices on this concept accelerate individual to be more innovative. By managing knowledge in a systematic way would also increase the awareness and benefits to both individuals and organizations. In advance, resources and information can be accessed quickly across the organization.

This study adopts the qualitative approach that applied for a literature review. Through this study, it is expected that the findings mentioned below would help Malaysian agencies and organizations to self-check respective factors based on trends and recent challenges so that the organization can get over the existing gaps. By referring to the current trends and challenges from this study, it is found that the most challenging factors in $\mathrm{KM}$ initiatives in both public and private agencies are as follows:

- Less management, leadership, and support.

- Individualism.

- Lack of training.

- Lack of teamwork.

- Human behavior.

Apart from identifying the challenges faced by the organization, it is also necessary to recognize and identify the level of how KM is being practiced now. As a recommendation, the maturity model will help the organization to identify the maturity level of knowledge management effectively. Thus, through this maturity model, the organization will have guidance and insights on where they are up to now. This will promote continuous improvement of their KM practices by looking at the level. Therefore, coherent frameworks and model for planning, management, and communication-based on continuous learning and accountability should be practiced. The framework or model proposed will improve KM performance by determining expected outcomes, as well as 
monitoring progress toward achievement, integrating new ideas in reporting on the performance of an organization.

\section{ACKNOWLEDGEMENT}

This research was sponsored by the Ministry of Education Malaysia under Fundamental Research Grant Scheme (FRGS/1/2018/ICT04/UKM/02/11) and PP-FTSM-2019 Universiti Kebangsaan Malaysia. We would like to thank for supporting and funding this research.

\section{REFERENCES}

[1] Z. Ahmed, M. Zulkefli, and A. Kamsuriah, "An analysis of knowledge management challenges in agile global software development," Journal of Telecommunication, Electronic and Computer Engineering (JTEC), vol. 9, no. 3-4, pp. 63-66, 2017.

[2] S.A.P. Ganapathy, and S. Abdullah, "Organizational readiness in adapting the knowledge management elements: Overview of the public sector in Malaysia", International Journal of Applied Engineering Research, vol. 10, pp. 97-102, 2015.

[3] Wiig, M. Karl, "Knowledge management: Where did it come from, and where will it go? " Expert systems with applications 13, no. 1, pp. 1-14, 1997.

[4] I. Nonaka and H. Takeuchi, The Knowledge-Creating Company: How Japanese Companie Create The Dynamics Of Innovation, Oxford university press, 1995

[5] A. Verna, The knowledge evolution. Routledge, 2012.

[6] P. A. Strassman, "Organizational productivity: The role of Information Technology," Information Processing 77, B. Gilchrist, Editor@ Ifip, North-Holland Publishing Company, 1977.

[7] K. Dalkir, Knowledge Management In Theory And Practice. Germany, Burlington, MA: Elsvier Butterworth-Heinemann, 2005.

[8] G. U. Orlu, M. Veeraiyah, K. Machap, and S. Ganapathy, "Adaptation of knowledge-based management practices for effectively use in academic planning system," Journal of Information Systems Technology \& Planning, vol. 7, no. 18, pp. 132, 2014.

[9] N. A. Kassim, M. F. Baharuddin, and Z. A Samad, "Knowledge Management Practices and Organizational Performance in Malaysia Government Institution," International Journal for Infonomics (IJI), vol. 9 , no. $4,2016$.

[10] J. Moshari, "Knowledge management issues in malaysian organizations: the perceptions of leaders," Journal of Knowledge Management, Economics and Information Technology, vol. 3, no.5, pp. 15-27, 2013.

[11] Abdullah and H. Date, "Public sector knowledge management: A generic framework," Public Sector ICT Management Review, vol. 3, no. 1, pp. 1-14, 2009.

[12] S. Yahya, and W. Goh, "Managing human resources towards achieving knowledge management," Journal of Knowledge Management, vol. 6, pp. 457-468, 2002.

[13] S. O. S. B. Syed-Ikhsan, and F. Rowland, "Knowledge management in a public organization: A study on the relationship between organizational elements and the performance of knowledge transfer," Journal of knowledge management, vol. 8, no. 2, pp. 95$111,2004$.

[14] T.S. Yu, "Can East Asia rise again? ," Journal of Asian Economics, vol. 13, no. 6, pp. 715-729, 2003.

[15] W. Chong, C. C. Chong, and Y. Wong, "Implementation of KM strategies in the Malaysian telecommunication industry: An empirical analysis." Vine, vol. 37, no. 4, pp. 452-470, 2007.

[16] C. W. Chin, C. C. Siong, and Y. W. Kuan, "Is the Malaysian telecommunication industry ready for knowledge management implementation?" Journal of knowledge management, vol.13, no. 1, pp. 69-87, 2009.

[17] N. A. Kassim, and N. A. Noreen, "Assessing knowledge management maturity in a telecommunication company," International Conference on Innovative Trends in Multidisciplinary Academic Research (ITMAR), vol. 1, pp. 21-32, 2014.

[18] L. T. Wai, and S. Hase, "Knowledge management in the Malaysian aerospace industry," Journal of Knowledge Management, vol. 11, no. 1, pp. 143-151, 2007.

[19] N. A. M. Ramin, K. M Taib, D. M. Hashim, S. A. Noordin, and S. M. Yasin, "Knowledge management implementation in a government research institute in Selangor, Malaysia," Communications of the IBIMA," vol. 1, 2013.

[20] M. B. Yaakub, K. Othman, and A. F. Yousif, "Knowledge management practices in Malaysian higher learning institutions: A review on selected cases," International Journal of Education and Research, vol. 2, no 1, pp. 1-10, 2014.

[21] E. M. A. B. A. Hashim, N. A. Talib, and K. M. Alamen, "Knowledge management practice in Malaysian construction companies," MiddleEast Journal of Scientific Research, vol. 21, no. 11, pp. 1952-1957, 2014.

[22] N. Mat, J. Alias, and N. Muslim, "Individual factors on knowledge sharing among academicians at Universiti Kebangsaan Malaysia (UKM)," Social Sciences (Pakistan), vol. 11, no. 19, pp. 4771-4775, 2016.

[23] C. C. Siong, "KM critical success factors: A comparison of perceived importance versus implementation in Malaysian ICT companies," The learning organization, vol. 13, no. 3, pp. 230-256, 2006.

[24] A. A. Mohamad, T. Ramayah, and M. C. Lo, "Knowledge management in MSC Malaysia: The role of information technology capability," International Journal of Business \& Society, vol. 18, pp. 651-660, 2017.

[25] C. Okoli, "A guide to conducting a standalone systematic literature review," Communications of the Association for Information Systems, vol. 37, 2015.

[26] K. Iskandar, M. I. Jambak, R. Kosala, and H. Prabowo, "Current issue on knowledge management system for future research: A systematic literature review," Procedia computer science, vol. 116, pp. 68-80, 2017.

[27] H. M. Ali, and Z. M. Yusof, "Acculturation of knowledge management initiative in commercial banks: The case of malaysia. asia-pacific," Journal of Information Technology and Multimedia, vol. 1, no. 1, 2012.

[28] R. Tasmin. (2012) Knowledge management: An empirical survey on Malaysia higher education. [Online]. Available: http://www. http://eprints.uthm.edu.my/id/eprint/2603/

[29] H. H. Mohammad, F. H. Mohammad, S. Ali, and N. A. B. Ali, "The influence of knowledge management capabilities on organizational performance: A study of private university in Malaysia," International Journal of Science and Research, vol. 2, no. $3,2012$.

[30] C. N. L. Tan, and Md. S. Noor, "Knowledge management enablers, knowledge sharing and research collaboration: A study of knowledge management at research universities in Malaysia," Asian Journal of Technology Innovation, vol. 21, no. 2, pp. 251-276, 2013.

[31] H. A. Bakar, R. Mahmood, and N. N. H. Ismail, "Effects of knowledge management and strategic improvisation on SME performance in Malaysia," Asian Social Science, vol. 11, no. 9, pp. 207, 2015.

[32] R. Ramlan, S. S. Omar, S. W. Chan, A. M. Yassin, and C. K. Joy, "Knowledge Management in NGOs: A preliminary study in Malaysia," Advanced Science Letters, vol. 21, no. 5, pp. 1579-1583, 2015.

[33] N. Mansor, H. C. M. Mohamad, and K. A. Nurmuslimah, "Knowledge sharing and organizational learning success in malaysia: A case of private sectors in state of Johor," Journal of Applied Environmental and Biological Sciences, vol. 6, pp. 21-28, 2016.

[34] T. T. Soon, J. Fisher, and F. A. Zainol, "An integrated view of knowledge management enablers, process and organizational performance in Malaysian enterprises," Asian Institute of Knowledge Management, vol. 1, no. 1, pp. 40-40, 2017.

[35] A. L. Abdullah, Z. M. Yusof, K. Ahmad, and U. A. Mokhtar, "The building blocks of electronic records and information management framework for Malaysia public agencies: Contexts and approaches," Journal of Fundamental and Applied Sciences, vol. 10, no. 3, pp. 738-753, 2018.

[36] S. Adam, B. Mahadi, S. A. Panatik, and A. Rahman, "The mediating role of knowledge management in e-business in Malaysia," AsiaPacific Management Accounting Journal, vol. 13, no. 2, pp. 1-25, 2018.

[37] I. A. Adeyemi, D. Martin, S. Eni, and A. Adeyemi, "Ascertaining the transfer of facility management knowledge to the development of new students' residential colleges in UTHM Malaysia," Journal of Technology Management and Business, vol. 6, pp. 9-24, 2019.

[38] N. Mat, J. Alias, and N. Muslim, "The impacts of organizational factors on knowledge sharing in higher learning instituitions (HLIs): Case at Universiti Kebangsaan Malaysia (UKM)," Mediterranean Journal of Social Sciences, vol. 7, no. 6, pp. 181, 2016. 